\title{
Verticillium wilt threatens coastal cauliflower crop
}

\author{
Steven T. Koike $\square$ Krishna V. Subbarao $\square$ R. Michael Davis $\square$ Thomas R. Gordon
}

\begin{abstract}
For the first time, cauliflower has been found to be a host of the destructive soil-borne pathogen Verticillium dahliae. Incidence of this disease is spreading throughout cauliflower-growing regions in coastal California, resulting in crop yield and quality losses. All of the tested cauliflower cultivars, both commercially available and experimental selections, were susceptible to the disease. Initial tests indicate that non-tarped fumigants are not effective against this disease.
\end{abstract}

In California, cauliflower is an important vegetable commodity, which is grown year-round on 38,550 acres in a six-county coastal region (Monterey, San Benito, San Luis Obispo, Santa Barbara, Santa Cruz and Ventura). This crop has an annual gross value of more than $\$ 158$ million. Important as both a fresh market and frozen vegetable commodity, cauliflower is also a major rotation crop for the sizable lettuce industry in the region.

In 1990 in the Salinas Valley, we observed symptoms on several cauliflower plantings that did not correspond with the commonly recognized diseases of the crop. By 1992 an additional 12 fields were affected. By 1994 the problem had been observed in numerous fields throughout the coastal area and it now threatens the cauliflower industry. Studies were initiated in 1990 to identify the cause of this disease and to explore possible management options.

Disease symptoms do not develop until the cauliflower matures and develops flower heads. At the heading stage, external symptoms consist primarily of yellowing of the older, lower leaves. This chlorosis moves up the stem and affects successively younger leaves. As the disease progresses, the older, yellowed leaves become brown, dry up and eventually fall off. During warm daytime periods, the entire canopy of leaves wilts. Affected plants are stunted and produce cauliflower heads that are small and of poor quality. The vascular tissues of stems and roots have extensive black discolored areas. Symptoms develop only on summer and fall cauliflower crops, and have not been observed during winter and early spring seasons.

\section{Identification of the pathogen}

We collected symptomatic cauliflower plants, removed all leaves and petioles, and surface-sterilized the remaining stems in $10 \%$ bleach (sodium hypoclorite) solutions. After removing the outer stem tissues, we placed small pieces of the underlying vascular tissue on water agar or acidified potatodextrose agar in an attempt to isolate pathogens. Verticillium dahliae colonies were consistently isolated from the diseased tissues.

To confirm that $V$. dahliae was the pathogen, we dipped roots of 30-dayold cauliflower plants (cv. 'White Rock') into conidial suspensions and planted them into pots. Control plants were dipped in sterile distilled water and planted the same way. Inoculated and control plants were grown both in greenhouse and growth chambers.

After 4 weeks, inoculated plants in both the greenhouse and growth chambers exhibited stunting, chlorosis, and defoliation of the oldest leaves. These plants also produced smaller, more numerous leaves than plants that had not been inoculated. Vascular discoloration of the stem was present in the inoculated plants, and $V$. dahliae was isolated from these tissues. Control plants were symptom- less and the pathogen was not recovered from plated stem tissue.

\section{Soil assays, disease incidence}

Soil samples were collected in the summer and fall seasons of 1991 to 1993 to determine inoculum levels of $V$. dahliae in the soil. Soil assays were designed to recover and enumerate microsclerotia - the pathogen's resilient resting structures present in the soil. Nine sample sites were located along an " $X$ " pattern that extended throughout each field. At each of the nine sample sites, a 10-by-10 $\mathrm{ft}^{2}$ area was marked and eight 10 -inch-deep soil cores were removed from plant rows using a 1-inch-diameter soil probe. The eight cores from each sample site were then bulked into one composite sample. All plants from these sections were then examined for vascular discoloration by making cross sections through the stems 2 inches above the soil line. The percentage of plants showing vascular discoloration was recorded. Plants with symptoms were randomly collected and tested for the presence of $V$. dahliae as described above. Because broccoli is closely related to cauliflower, soil samples and vascular discoloration data were also collected from broccoli fields in the same areas of the Salinas Valley.

Soils were air-dried in the laboratory for 6 weeks, then mixed thoroughly and analyzed for the presence of viable microsclerotia using the modified Anderson sampler method. Soils were placed onto a Verticilliumselective medium (Sorenson's NP-10).

For the 10 cauliflower fields surveyed, soil inoculum density ranged from 2.2 to 92.9 microsclerotia / $g$ of soil (table 1). While high inoculum densities (greater than 35 microsclerotia/g) were consistently associ- 


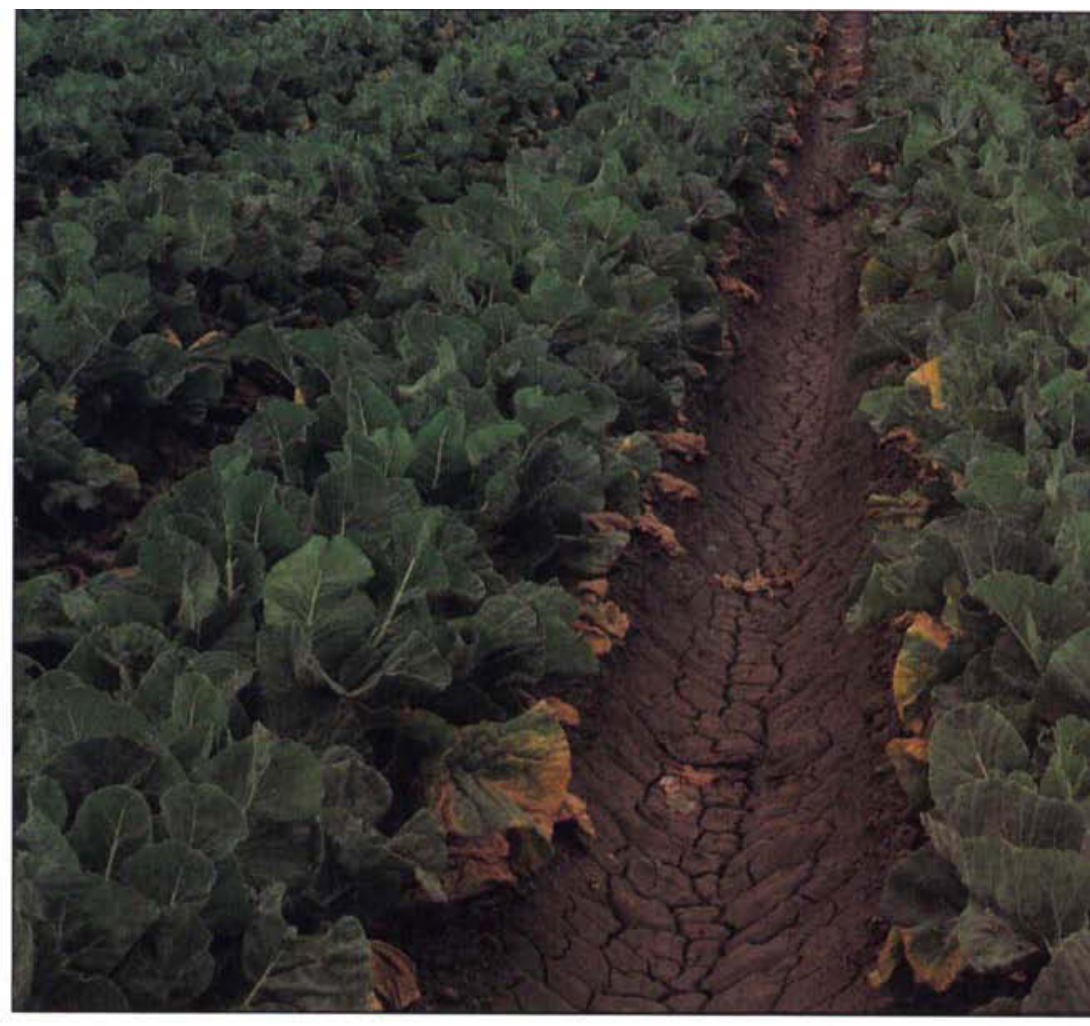

ated with a high percentage of plants having symptoms, an inoculum density of only 5 microsclerotia/g of soil was associated with $98 \%$ of the plants that had vascular discoloration. Verticillium dahliae was consistently isolated from symptomatic cauliflower plants collected from the 10-by- $10 \mathrm{ft}^{2}$ sample areas. However, even though soil collected from broccoli fields contained as much as $80.3 \mathrm{microsclerotia/g}$ soil (table 1), broccoli plants showed no leaf chlorosis or leaf drop. While occasional vascular discoloration was observed in broccoli stems, $V$. dahliae was not recovered from broccoli tissue.

\section{Cultivar evaluation}

To test cauliflower cultivars for resistance to $V$. dahliae, two cultivar trials were conducted each year from 1991 to 1993 in commercial cauliflower fields in the Salinas Valley. Cultivars were planted in randomized complete block designs, with six replications each in 1991 and 1992 trials, and five in 1993. Each plot consisted of one bed 40 inches wide and 20 feet long. The cauliflower cultivar 'White Rock' was included in all trials since it is one of the most widely planted selections, and also highly susceptible to Verticil-
As cauliflower matures, the lower leaves of Verticilliuminfected plants turn yellow.

As disease progresses, lower leaves turn brown and fall off.

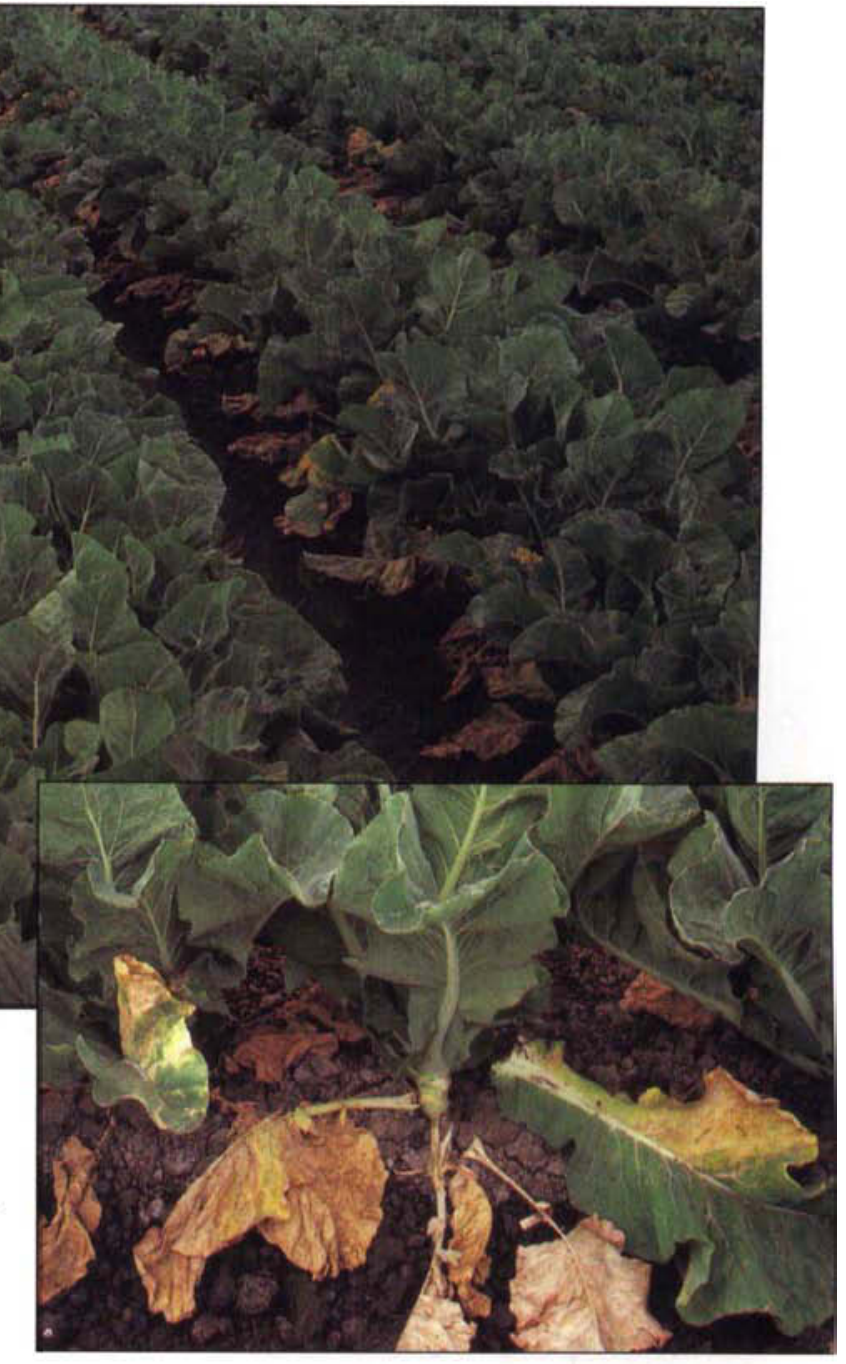

TABLE 1. Site, crop, vascular discoloration incidence, and microsclerotia per gram of soil for different fields in the Salinas Valley in 1991-1993

\begin{tabular}{llcc}
\hline Field & Crop & Discoloration & $\begin{array}{c}\text { Microsclerotia/gram } \\
\text { soil }\end{array}$ \\
\hline & & $\%$ & mean \pm S.E. \\
\hline Harris Y & Cauliflower & 4.7 & $10.0 \pm 0.31$ \\
Harris S & Cauliflower & 94.2 & $12.7 \pm 2.82$ \\
Hw 68 & Cauliflower & 6.9 & $3.0 \pm 0.47$ \\
Foster & Cauliflower & 96.8 & $7.1 \pm 0.31$ \\
Abbot & Cauliflower & 98.4 & $2.6 \pm 0.63$ \\
Toro & Cauliflower & 10.6 & $92.9 \pm 8.70$ \\
R1 & Cauliflower & 94.0 & $87.7 \pm 1.20$ \\
R12 & Cauliflower & 95.0 & $35.9 \pm 0.35$ \\
R17 & Cauliflower & 100.0 & $7.7 \pm 0.16$ \\
Hitchcock & Cauliflower & 37.6 & $32.0 \pm 0.00$ \\
Hunter 6 & Broccoli & 0.0 & $80.3 \pm 3.92$ \\
Hunter L & Broccoli & 0.0 & $29.3 \pm 2.51$ \\
Nashua & Broccoli & 0.0 & $3.7 \pm 0.16$ \\
Pan Hill & Broccoli & 0.6 & $3.1 \pm 0.31$ \\
Mer Bluff & Broccoli & 2.5 & $3.4 \pm 0.88$ \\
Pan Front & Broccoli & 8.6 & \\
\hline
\end{tabular}

- The percentage of plants which, when cut transversely 2 inches above the soil line, revealed vascular discoloration. In each field, cauliflower or broccoli plants in nine plots of $10-b y-10 \mathrm{ft}^{2}$ were evaluated. For cauliflower plants, $V$. dahliae was consistently isolated from randomly collected plants. However, this pathogen was not recovered from broccoli plants even though occasional vascular discoloration was observed. $\dagger$ Mean microsclerotia/g of soil \pm standard error of means. Soil samples were collected from the same nine evaluation plots in each field. Eight 10-inch-deep cores were taken per plot and bulked into a composite sample. Samples were dried and tested for $V$. dahliae. 
TABLE 2. Severity ratings of cauliflower and other cole crop cultivars for Verticillium wilt at five locations, 1991-1993*

\begin{tabular}{|c|c|c|c|c|c|c|}
\hline & \multicolumn{6}{|c|}{$\begin{array}{l}\text { Severity ratings } \\
\text { Field and year of test } \dagger\end{array}$} \\
\hline & \multicolumn{2}{|c|}{ 1991‡ } & \multicolumn{2}{|c|}{$1992 \S$} & \multicolumn{2}{|c|}{1993 | } \\
\hline & R1 & Pan 6 & R17 & Blum. & R1 & $A C$ \\
\hline \multicolumn{7}{|l|}{ Cauliflower } \\
\hline Aubade & 1.9 & 1.0 & & ... & $\ldots$ & $\ldots$ \\
\hline Avalanche & 1.8 & 0.1 & 1.5 & 1.5 & 3.6 & 3.9 \\
\hline B1390 & ... & ... & $\ldots$ & $\ldots$ & 4.2 & 3.5 \\
\hline Blue Diamond & 2.0 & 1.0 & ... & $\cdots$ & $\ldots$ & $\ldots$ \\
\hline Broccoflower & 2.0 & $\ldots$ & $\ldots$ & $\ldots$ & 5.8 & 5.9 \\
\hline Candid Charm & 1.9 & 0.5 & 1.6 & 1.3 & 3.3 & 3.1 \\
\hline Cashmere & ... & 0.9 & 1.9 & 1.7 & ... & ... \\
\hline CF 11 & ... & ... & 1.8 & 1.8 & ... & ... \\
\hline $\operatorname{cs} \times 12$ & $\ldots$ & $\cdots$ & 1.9 & 1.9 & & $\ldots$ \\
\hline Earli-snow & $\ldots$ & $\ldots$ & 1.6 & 1.4 & 2.7 & 3.0 \\
\hline Fargo & $\ldots$ & $\ldots$ & $\ldots$ & $\ldots$ & 4.2 & 3.4 \\
\hline Floriade & 1.4 & 0.8 & 1.4 & 1.7 & 2.6 & 2.8 \\
\hline HMX0189 & ... & ... & ... & ... & 3.8 & 4.1 \\
\hline HMX1160 & ... & ... & ... & $\ldots$ & 4.1 & 4.5 \\
\hline HMX1161 & $\ldots$ & $\ldots$ & $\ldots$ & $\ldots$ & 2.9 & 3.0 \\
\hline Igloo & $\ldots$ & ... & 1.5 & 1.7 & 3.1 & 2.8 \\
\hline Incline & $\ldots$ & $\ldots$ & ... & $\ldots$ & 4.2 & 3.9 \\
\hline Lateman & 2.0 & $\ldots$ & $\ldots$ & $\ldots$ & $\ldots$ & $\ldots$ \\
\hline NVH1510 & ... & ... & ... & ... & 3.6 & ... \\
\hline NVH1511 & $\ldots$ & $\ldots$ & $\ldots$ & $\ldots$ & 4.3 & ... \\
\hline Paleface & 1.8 & 1.3 & $\ldots$ & $\ldots$ & ... & ... \\
\hline PSX 104689 & $\ldots$ & ... & 1.6 & 0.9 & $\ldots$ & $\ldots$ \\
\hline PSX 518789 & ... & ... & 1.8 & 1.9 & $\ldots$ & $\ldots$ \\
\hline Pybas 741 & $\ldots$ & $\ldots$ & 1.9 & 2.0 & 4.9 & $\cdots$ \\
\hline Pybas 184 & 2.0 & 1.1 & 1.8 & 1.9 & ... & ... \\
\hline Ravella & 1.7 & ... & ... & ... & $\ldots$ & $\ldots$ \\
\hline RS1 & $\ldots$ & ... & ... & ... & 2.5 & 2.1 \\
\hline RS2 & $\ldots$ & $\ldots$ & $\ldots$ & $\ldots$ & 2.5 & 2.7 \\
\hline Rushmore & 1.9 & $\ldots$ & $\ldots$ & $\ldots$ & $\ldots$ & $\ldots$ \\
\hline Sentinel & $\ldots$ & $\ldots$ & ... & ... & 3.1 & 2.8 \\
\hline Serrano & 2.0 & 1.4 & $\ldots$ & $\ldots$ & $\ldots$ & $\ldots$ \\
\hline Silverstar & 2.0 & 0.9 & 1.9 & 1.8 & 4.1 & 3.9 \\
\hline Snowball 123 & 1.9 & 1.0 & 1.7 & 1.9 & $\ldots$ & $\ldots$ \\
\hline Snowball 184 & $\ldots$ & $\ldots$ & $\ldots$ & $\ldots$ & 3.5 & 4.2 \\
\hline Snowball Elite & 2.0 & 0.9 & 1.9 & 1.8 & $\ldots$ & $\ldots$ \\
\hline Snow Crown & 1.7 & ... & $\ldots$ & $\ldots$ & $\ldots$ & $\ldots$ \\
\hline Snowman & 1.6 & 0.3 & 1.3 & 1.7 & 3.3 & 4.3 \\
\hline Snow March & 1.7 & 1.1 & $\ldots$ & $\ldots$ & ... & $\ldots$ \\
\hline Snow Mystique & $\ldots$ & ... & $\ldots$ & $\ldots$ & 4.7 & 4.7 \\
\hline White Magic & $\ldots$ & $\ldots$ & 2.0 & 1.9 & 4.7 & 4.2 \\
\hline White Rock & 2.0 & 1.4 & 1.8 & 1.9 & 4.8 & 4.7 \\
\hline XP $6 Y B C$ & $\ldots$ & ... & $\ldots$ & $\ldots$ & 3.1 & 3.2 \\
\hline XP 6YDL & $\ldots$ & $\ldots$ & $\ldots$ & $\ldots$ & 4.2 & 4.4 \\
\hline Yukon & 2.0 & $\cdots$ & 2.0 & 2.0 & 4.7 & $\cdots$ \\
\hline \multicolumn{7}{|l|}{ Other } \\
\hline Bok choy & 2.0 & $\ldots$ & $\ldots$ & $\ldots$ & 6.0 & 6.0 \\
\hline Chinese cabbage & 2.0 & $\ldots$ & $\ldots$ & $\ldots$ & 6.0 & 6.0 \\
\hline Grenade (cabbage) & $\ldots$ & 1.5 & ... & $\cdots$ & 2.7 & 3.3 \\
\hline $\operatorname{LSD}(P=0.05)$ & 0.3 & 0.3 & 0.3 & 0.4 & 0.6 & 0.7 \\
\hline
\end{tabular}

"The seven broccoli cultivars monitored showed occasional blackening of the vascular system, but no other symptoms were seen on the plants. Verticillium dahliae was not recovered from broccoli vascular tissues. tPreplanting mean number of microsclerotia/g of soil \pm standard error of means for the corresponding fields were the following, respectively: $92.9 \pm 8.7$ and $42.4 \pm 2.3$ (1991), $30.7 \pm 1.0$ and $5.9 \pm 1.6$ (1992), $38.7 \pm$ 3.8 and $16.5 \pm 0.7(1993)$

fFor the 1991 trial, six mature plants were evaluated in each plot by making cross sections through the stems 2 inches above the soil line and determining the extent of the discoloration of the vascular ring. Disease severity was rated using the following scale: $0=$ no vascular discoloration; $1=<50 \%$ of the vascular ring showing discoloration; $2=\geq 50 \%$ of the vascular ring showing discoloration. Values given are the average of 36 plants.

§The 1992 trial was evaluated in the same way as the 1991 trial.

IFor the 1993 trial, 10 mature plants were evaluated per plot by making longitudinal cuts down the center of the main stem, crown, and root and determining the extent of the discoloration of vascular tissue. The scale was weighted for the degree of discoloration as well as the height to which infection had moved. Disease severity was rated using the following scale: $1=$ no vascular discoloration; $2=1-10 \% ; 3=11-25 \% ; 4=26$ $50 \% ; 5=51-75 \% ; 6=76-100 \%$. Values given are the average of 50 plants. lium wilt. Selected trials also contained bok choy, broccoli, cabbage and Chinese cabbage. At each site, soil samples were collected and analyzed for the number of microsclerotia per gram of soil as described previously.

At crop maturity, cultivars were evaluated for severity of disease. In the 1991 and 1992 trials, six plants were evaluated in each plot by making cross sections through the stems 2 inches above the soil line and determining the extent of discoloration in the vascular ring. Disease severity was rated using the following scale: $0=$ no vascular discoloration; $1=<50 \%$ of the vascular ring showing discoloration; $2=\geq 50 \%$ of the vascular ring showing discoloration. For the 1993 trial, evaluations were made on 10 plants per plot by making longitudinal cuts down the center of the main stem, crown and root, and determining the extent of vascular discoloration. The scale was weighted for the degree of discoloration as well as the height to which the infection had moved. Disease severity was rated using the following scale: $1=$ no vascular discoloration; $2=1-10 \% ; 3=11-25 \% ; 4=$ $26-50 \%$; $5=51-75 \% ; 6=76-100 \%$.

All cauliflower cultivars included in the trials were found to be susceptible to Verticillium wilt, exhibiting leaf yellowing, leaf drop and vascular discoloration symptoms (table 2). The cultivars varied in their susceptibility. Bok choy, cabbage and Chinese cabbage were also highly susceptible to the pathogen, showing similar disease symptoms, with Verticillium dahliae isolated from vascular stem tissue of these plants. Broccoli exhibited occasional blackening of the vascular system, but no leaf yellowing, defoliation, wilting, or stunting. Verticillium dahliae was not recovered from broccoli vascular tissue plated onto microbiological media.

\section{Bed fumigation treatments}

Previous research and commercial practices have shown that tarped soil fumigation can be an effective treatment to manage Verticillium wilt in crops such as strawberries. However, the cost of fumigant and plastic tarp is 


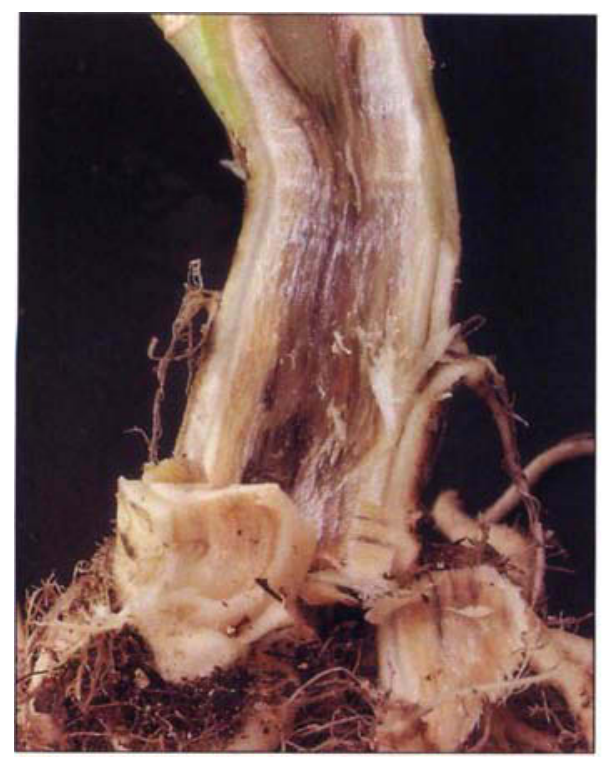

generally prohibitive for vegetable crops such as cauliflower; so we conducted a study in which we attempted to control Verticillium wilt in cauliflower using non-tarped, bed-applied fumigants. The experiment was done in a commercial field with a history of cauliflower Verticillium wilt. Soil type was a Salinas clay loam. Experimental design was a randomized, complete block with four replications. Each plot consisted of four beds 40 inches wide and 200 feet long. Fumigants were shanked into preformed beds by a commercial applicator on July 2, 1994, and left untarped. Three shanks per bed were used with each shank containing multiple exit ports. Treatments were the following: Tri-Clor (chloropicrin, $200 \mathrm{lb} / \mathrm{ac}$ ); Tri-Con 50/50 (methyl bromide + chloropicrin, $400 \mathrm{lb} / \mathrm{ac}$ ); Vapam (metam sodium, $60 \mathrm{gal} / \mathrm{ac}$ ); Mocap 69\% EC (ethoprop, $25 \mathrm{gal} / \mathrm{ac}$ ); untreated control.

Two weeks after application, the susceptible cauliflower cultivar 'White Rock' was transplanted into the plots. Disease severity was again rated at crop maturity using the 1993 rating system. Plots were also harvested three times to collect and count number 12-sized flower heads. Head counts from the three harvests were added to derive a total harvest figure.

Bed fumigation treatments failed to significantly reduce Verticillium wilt severity, and no treatment significantly increased cauliflower yields compared to control plots. Tri-Clor and Tri-Con 50/50 treatments resulted

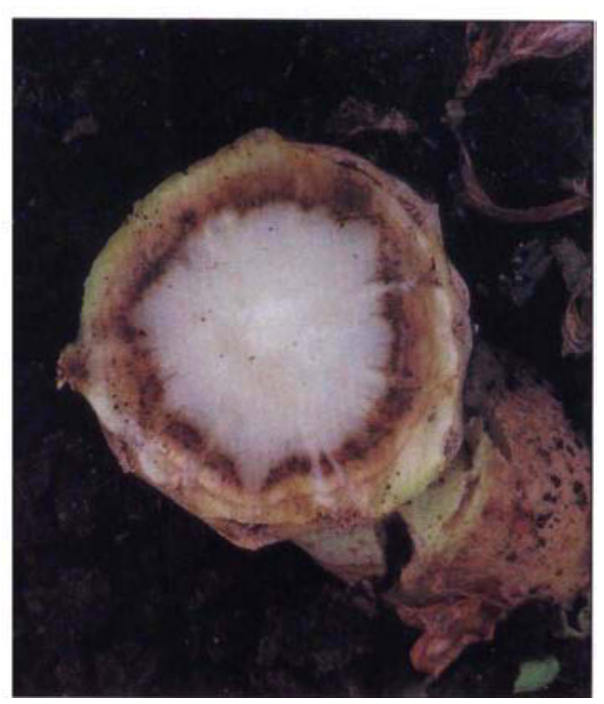

Longitudinal section cuts (far left) and cross-section cuts (near left) of cauliflower stems reveal the characteristic black vascular discoloration of Verticilliuminfected cauliflower.

Below, vascular discoloration can also be seen in the roots of infected cauliflower plants.

in the lowest disease ratings, but these ratings were not statistically different than those of untreated plots.

\section{Long-term implications}

Verticillium wilt represents a new disease to cauliflower in California. The disease occurs throughout the Salinas Valley, and also is present in other coastal growing areas such as the Lompoc, Pajaro, and Santa Maria valleys. All tested cauliflower cultivars, both commercially available and experimental selections, are susceptible to the disease. Untarped bed fumigation treatments were ineffective and are unlikely to provide satisfactory control of Verticillium wilt at the rates used in this experiment. The ability of $V$. dahliae to survive in soils for long periods of time as microsclerotia, the lack of resistant cultivars, and the prohibitive cost or future unavailability of soil fumigants, indicate that Verticillium wilt may be a long-term problem for the cauliflower industry.

Since Verticillium wilt of cauliflower only occurs in the summer and fall crops, growers may capitalize on this phenomenon by scheduling winter/spring plantings in infested fields while avoiding such fields for summer/fall cauliflower.

Additional research efforts will include determining the host range of the cauliflower isolates of $V$. dahliae, investigating whether these isolates are a distinct strain of $V$. dahliae, and evaluating the use of broccoli amendments for reducing soil inoculum levels.

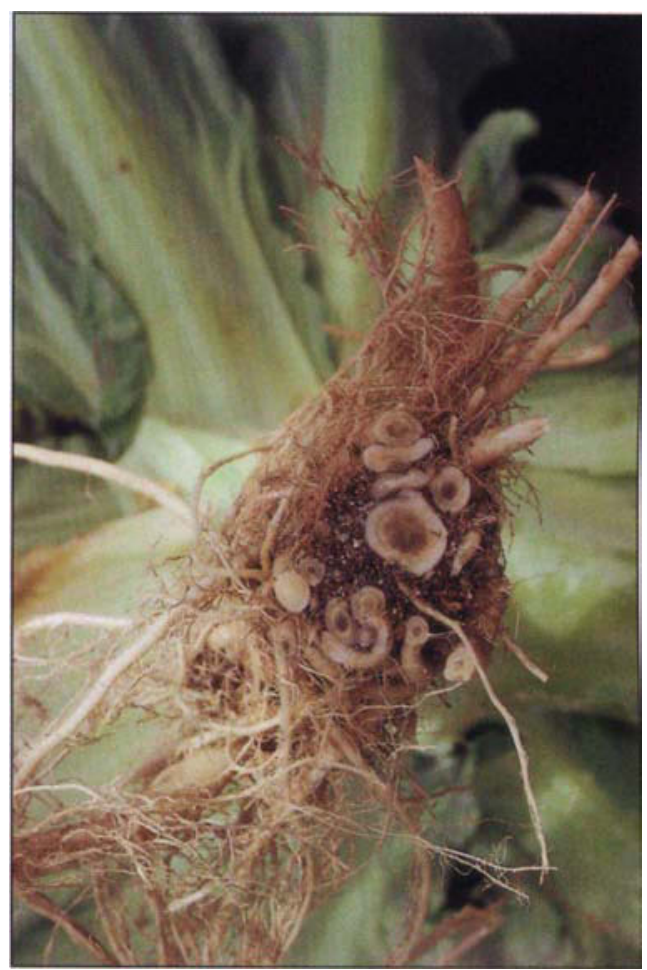

S.T. Koike is Plant Pathology Farm Advisor, UC Cooperative Extension, Monterey and Santa Cruz counties; K.V. Subbarao is Assistant Plant Pathologist/Cooperative Extension Specialist, Department of Plant Pathology, UC Davis, and located at U.S. Agricultural Research Station, Salinas; R.M. Davis is Plant Pathology Specialist, Department of Plant Pathology, UC Davis; and T.R. Gordon is Associate Professor, Department of Environmental Science, Policy and Management, UC Berkeley.

The authors thank J. Aragon, S. Bassi, A. Caminay, S. Dacuyan, J.E. DeVay, K. Dunster, K. Fowler, T.G. Gonzales, D. Lindsay, P. Niday, E. D. Oakes, J. Manassero, M. Mulanax, R. Miller, E.J. Paplomatas, S. Ray, B. Taylor, J. Taylor, M. Vidauri, J. Wakeman, and California cauliflower growers.

This research was partially supported by grants from the UC DANR Special Grants Program and from the California cauliflower industry. 